\title{
Subjective Well-Being among Institutionalized and Non- Institutionalized Senior Citizens
}

\author{
Dr. Dev Ashish ${ }^{1}$, Prof M. Ghufran ${ }^{2}$
}

Keywords: Subjective Well-Being, Institutionalized, Non- Institutionalized, Senior Citizens

The concept of subjective well-being has ever been a matter of intense debate and it has always cogitated the minds of great thinkers all over the world ever since the inception of human civilization .Still it is difficult to define it comprehensively as to what constitutes good life. It varies from individual to individual as some people think material wealth is the source of happiness where as for others, it is renunciation. In fact, the Weser and the Eastern cultures are markedly different on the issue of subjective well-being as the former has always gone for how much more it can have and the later struggled for the least requirement of life. Naturally, the dichotomy is science versus religion or more precisely, it is materialism versus spiritualism. The result is that the West has developed the empirical science and the East has excelled in spirituality. Thus, the overall culture influences the mass into grasping the philosophy of subjective well-being on the average. That's why the count on subjective well-being may be subjected to external or internal factors like sense-pleasure, human relationship, love-needs, material gain or renunciation leading to spiritual upliftment.

Stock et al in their scholarly work defined happiness as: "The degree to which an individual judges the overall quality of his life as-a-whole favorably (Veenhoven: 1984). Further, it is clarified that:"Subjective well-being is an abstract, super ordinate construct entailing the affective reactions of individuals along a positive-negative continuum to their life experiences" (Stock, Okun, \& Benin: 1986). The evaluation of subjective well-being has its roots in the cognitive process in any individual which is inherited by birth and enriched by environment. Thus, life satisfaction issuing from cognitive judgments and the play of moods and emotions issuing from affective evaluations are both considered for the study of SWB. Generally, people are said to have high SWB if they are satisfied with the circumstances of life that includes both the achieved and ascribed status. Literally the term happiness is used in place of its psychological terminology as SWB and people with frequent positive emotions are said to be happier than those experience more of negative emotions.

\footnotetext{
${ }^{1}$ Kumaun university, Nainital, Uttrakhand, India

${ }^{2}$ Kumaun university, Nainital, Uttrakhand, India

*Responding Author

(C) 2016 I A Dev, M Gufran; licensee IJIP. This is an Open Access Research distributed under the terms of the Creative Commons Attribution License (http://creativecommons.org/licenses/by/2.0), which permits unrestricted use, distribution, and reproduction in any Medium, provided the original work is properly cited.
} 


\section{Subjective Well-Being among Institutionalized and Non- Institutionalized Senior Citizens}

Of late, the scientific study of subjective well-being since past two decades has shown increasing interest in studying the negative emotions for the measure of SWB. So, radical behaviorism of earlier decades as study of SWB has modified itself toward more comprehensive results. Psychological articles researching on negative states for the measure of SWB outnumber those examining positive states by a ratio of 17 to 1 (Myers \& Diener : 1995).

If we discuss about subjective well-being among senior citizens we find that all of us want to live a long life, but no one wants to get old. As ridiculous it seems, the same ironic it is. Because instead of enjoying the beautiful dusk of life. Most of elderly people are trapped in Falsehood. Anxieties, uncontrolled nostalgia, irrational assessment of life are main among these. Because of this the desire of elderly people to live a free and unrestrained life without having any responsibility remains unfulfilled. And from this emerges the decline in qualitative life and absence of subjective well-being.

Keeping these dilemmas in mind, researcher has created his research's frame work. It is anticipated that this research work will come out with important results for the welfare of elderly people. So that elderly people either living with family or in old age homes can enjoy this beautiful dusk of life having subjective well-being.

\section{REVIEW OF LITERATURE}

Ku, McKenna, and Fox (2007) studied dimensions of subjective well-being and effects of physical activity in Chinese older adults. Subjective well-being (SWB) and its relationship with physical activity have not been systematically investigated in older Chinese people. So They explored these issues using qualitative interviews with a purposive sample of 23 community dwelling Chinese older adults (age 55-78 y, 12 women); 16 were physically active and 7 physically inactive. Using cross-case analyses, 7 dimensions of SWB emerged: physical, psychological, developmental, material, spiritual, sociopolitical, and social. Although elements of SWB may be shared across cultures, specific distinctions were identified. Active respondents reported the unique contributions of physical activity to the physical, psychological, developmental, and social elements of SWB. The findings suggest that physical activity could enhance the quality of life in Chinese older adults.

Singh and Dinesh (2009) conducted a study on health cognitions and subjective well-being in middle-aged and older adults. Health cognition stand for one's beliefs, perceptions, attribution meaning about health perceived status and complaints. Subjective well-being involves the study of what lay people might call happiness and satisfaction. In the study, psychological variables related to health have been studied in 132 rural participants above 55 years of age (Male 64 female 68). In order to compare the age effect on health beliefs, perception of health status, subjective well-being (happiness, life satisfaction, optimism), occurrence of somatic complaints and psychological distress symptoms the sample was divided into middle aged group comprised of 72 participants while there were 60 participants in older. The difference between sexes has also been tested for various variables separately and in interaction with age.

Doumit and Nasser (2010) conducted a study on quality of life and wellbeing of the elderly in Lebanese nursing homes. The purpose of their study was to assess quality of life in relation to wellbeing among Lebanese nursing home elderly residents. The study attempted to understand 


\section{Subjective Well-Being among Institutionalized and Non- Institutionalized Senior Citizens}

the impact of structures, processes and skills on elderly health status. For this purpose 220 normally functioning elderly respondents from 33 nursing homes were studied. A quasiexperimental approach measured psychological and health-related factors using the Geriatric Depression Scale, Activity of Daily Living, EuroQol EQ-5D and the Mini-Nutritional Assessment (MNA) instruments. A relatively high level of mild depression among elderly residents and a lack of mobility were found. Generally, normally functioning elderly residents were well nourished and had moderate daily activity levels. They claimed that the study is original in the sense that it assesses elderly residents' psychological and physical health status in relation to institutional structures, processes, and skills.

Bockerman, Johansson and Saarni (2011) conducted a study on Institutionalisation and subjective wellbeing for old-age individuals: is life really miserable in care homes? The purpose of the their study was to examines whether there are systematic differences in the quality of life, depending on whether an individual is institutionalised or not, holding health status and income level constant. In doing this they used a nationally representative data set, the health in Finland. When controlling for health and functional status, demographics and income level, they found that individuals who are living in old-age homes actually report significantly higher levels of subjective wellbeing than those who are living at home. We argue that this finding emerges from queuing for care homes. This implies that there are individuals living at home who are so frail that they should really be living in an old-age institution, but because of the queues for that particular mode of living, they are living at home with a decreased quality of life as a consequence.

Patil and Itagi (2013) conducted a study on subjective well-being status among institutionalized and non institutionalized senior citizens. The study was carried out on 140 respondents belonging to 60 years and above age group living in old age homes $(n=65)$ and with family $(n=75)$ and the sample was randomly selected from Hubli-Dharwad city, Karnataka with an objective to compare the level of subjective well-being among institutionalized and non-institutionalized senior citizens and to know the factors influencing subjective well-being among both senior citizens. Results of the study revealed that institutionalized senior citizens had more of wellbeing and non-institutionalized had more of overall subjective well- being and ill- being status. Among institutionalized, education (along with gender and age) and age (socio-economic status, financial support and family type) significantly influenced the well- being and ill- being respectively. Education (along with age, socio- economic status and financial support) and gender (along with age, socio- economic status and financial support) significantly influenced the illbeing status of non-institutionalized senior citizens. It was interesting to note that none of the variables significantly influenced the well- being status.

Gull \& Dawood (2013) conducted a study on religiosity and subjective well-being among institutionalized elderly in Pakistan. The study was con-ducted in 2012 which examined the relationship between religiosity and subjective well being amongst institutionalized elderly people. Data was collected from 100 adults above the age of 60 years in Lahore, Pakistan, through purposive sampling strategy. Religiosity was measured through Religiosity Index, while Trait Well Being Inventory was used to assess subjective well being. Pearson product moment correlation coefficient and regression analysis were used for the analysis of the data, which revealed that religiosity has a significant positive relationship with life satisfaction. However, no

(c) The International Journal of Indian Psychology, ISSN 2348-5396 (e)| ISSN: 2349-3429 (p) | 125 


\section{Subjective Well-Being among Institutionalized and Non- Institutionalized Senior Citizens}

association was found between religiosity and mood level. Moreover, regression analysis indicated that religiosity positively predicted life satisfaction among elderly.

\section{Aims of the study}

- $\quad$ To explore the difference between institutionalized and non-institutionalized senior citizens on subjective well-being.

- $\quad$ To explore the difference between male and female senior citizens on subjective wellbeing.

- $\quad$ To explore the interactional effect between residential status and gender on subjective well-being.

\section{Hypothesis of the study}

- $\quad$ There would be significant difference between institutionalized and non-institutionalized senior citizens on subjective well-being.

- $\quad$ There would be significant difference between male and female senior citizens on subjective well-being.

- $\quad$ There would be significant interactional effect between residential status and gender on Subjective well-being.

\section{METHODOLOGY}

The total sample was consisted of 240 subjects in which 120 were non-institutionalized and 120 were institutionalized old age subjects age ranging 60 to 75. Among 120 subjects of noninstitutionalized conditions there were 60 males and 60 females. The non-institutionalized subjects were those subjects who were living in the home with their family. Among 120 institutionalized subjects 60 subjects were males and 60 subjects were females. The institutionalized old age subjects were from 5 different old age homes situated in Uttrakhand.

\section{Tool used}

For measuring Subjective well-being of Senior citizens Sell and Nagpal's The subjective willbeing inventory (SUBI) will be used the Inventory in Consisted of 40 items and measures 11 dimensions of subjective well-being, a namely General well-being-positive affect, Expectationachievement congruence, Transcendence, Family group support, Social support, Primary group concern, Inadequate mental mastery, Perceived ill-health, Deficiency in social contacts, General well-being-negative affect. This scale has high inter-rater reliability, inter-scores reliability, and test-retest reliability. The scale has been found to be highly significant and satisfactory in validity. Patil, M.S. and Halyal, P.S (1999) have reported that the test retest reliability of the SUBI inventory is 0.79 and the validity is 0.86 .

\section{Statistical method}

There were two independent variables varied in two ways. So a $2 * 2$ factorial design was used. Fratio was calculated to study separate and interactional effects of residential status and gender on the dependent variables. 
RESULTS AND DISCUSSION

Table- 1: Summary of analysis of variance for subjective well-being.

\begin{tabular}{|l|l|l|l|l|l|}
\hline Source of variance & $\begin{array}{l}\text { Sum of } \\
\text { squares }\end{array}$ & Df & Mean square & F & $\begin{array}{l}\text { Level of } \\
\text { Significance }\end{array}$ \\
\hline Residential status (A) & 8027.27 & 1 & 8027.27 & 20.98 & .01 \\
\hline Gender (B) & 3936.60 & 1 & 3936.60 & 10.29 & .01 \\
\hline Interaction (AxB) & 567.267 & 1 & 564.267 & 1.47 & $\mathrm{NS}$ \\
\hline Error & 90295.79 & 236 & 382.6 & & \\
\hline
\end{tabular}

Table- 2: Mean and S.D of four groups on subjective well-being.

\begin{tabular}{|l|l|l|l|}
\hline Groups & Mean & S.D & N \\
\hline Non-institutionalized male Ss & 73.48 & 15.26 & 60 \\
\hline Non-institutionalized female Ss & 68.45 & 15.34 & 60 \\
\hline Institutionalized male Ss & 64.98 & 13.44 & 60 \\
\hline Institutionalized female Ss & 60.48 & 10.31 & 60 \\
\hline
\end{tabular}

Table 3: Mean of means for subjective well being.

\begin{tabular}{|l|l|l|l|}
\hline Groups & $\begin{array}{l}\text { Non- } \\
\text { institutionalized }\end{array}$ & Institutionalized & Aggregate Mean \\
\hline Male & 73.48 & 64.98 & 69.23 \\
\hline Female & 68.45 & 60.48 & 64.46 \\
\hline Mean & 70.96 & 62.73 & 66.84 \\
\hline
\end{tabular}

Table 1 reveals that F-ratio for the main effect of residential status on subjective well-being is 20.98, which is statistically significant at 0.01 level of confidence. The finding indicates that non-institutionalized subjects and institutionalized subjects differ significantly on subjective well-being. As the table 3 depicts that the mean score of non-institutionalized subjects on subjective well being is 70.96 and the mean score of institutionalized subjects on subjective wellbeing is 62.73. This result indicates that non-institutionalized subjects are higher in their subjective well-being than institutionalized subjects. When we think of study all the items of scale and responses on the old men and statistical analyses, the fact comes out that the living place has significant effect on subjective-well-being. Since living place is such a stimulus that is not only a stimulus but it is an amalgam of them that glows emotions in a man in many different ways and these emotions causes psychological stable and transient (unstable) changes in the man. We can understand it in a different way that an old man finds it very difficult to reside in a shelter that is made for old men because the old man does not feel easy when he leaves the place, the neighbor's friends, relations, colleagues of society with whom he has lived so many years. On this stage of the age, it is very challenging to accept the changes according to the new atmosphere. Moreover, in spite of rich material and medical facilities senior citizens living in old age homes feel the lack of emotional security because they have seen their children growing like plant and have struggled a lot to make them able to live in this competitive world. So their attachment is natural with their sons, daughters, grandsons, granddaughters and daughter and spiraling from them compel them to live life loneliness and grumbling. 


\section{Subjective Well-Being among Institutionalized and Non- Institutionalized Senior Citizens}

The most important fact is that in spite of changing social values and standards old men are not ready to accept the shelter because our society as well as old men is not taking shelter as an alternative to old age the reason is our society up to considerable extent, is bases on traditional values. Even today the instance/example of Sravan Kumar and Devvrata is prevailed in our mind. So it is very difficult for old men to accept the rapidly changing social patterns, values and standards.

Contrary to it in Home base elderly all above mentioned negative stimulus are not found and comparatively they are more attached. It happens because society considers that going to a shelter is a failure of relationship between guardians and sons. Since the home bases elderly live with their family members, so they have the valid reason of satisfaction. Thus, significant difference of subjective well being between institutionalized elderly and home-bases elderly is natural.

This result of the study is in consistent with the result obtained by earlier investigators for example Chakrabarti (2009) elderly living in family setting are having more subjective wellbeing and level of satisfaction scores as compared to elderly living in old age homes. Contrary to these supportive studies, which show the sheer opposite effects conducted by Suvera (2012) the psychological well-being of the institutionalized and non-institutionalized aged cannot be predicted on the basis of their residence. Petri \& Saarni (2011) found that who live in old people's homes actually report significant higher level of subjective well-being than those who live at home.

Table 1 further reveals that the F-ratio for the main effect of gender on subjective well-being is 10.29 , which is statistically significant at .01 level of confidence. The finding indicates that male subjects and female subjects differ significantly on subjective well-being. As table 3 depicts that the mean score of male subjects on subjective well-being is 69.23 and the mean score of female subjects on subjective well being is 64.23. This result indicates that male subjects are higher in their subjective well-being than female subjects. we saw a significant effect gender on subjective well being because society, especially in India- a progressive but traditional society not only divide the roles of male and female, but also pressurize them to stick to their roles and boundary. The boundaries of males and females up to considerable extent are fixed and rigid even today. Roughly, from a person of same gender, in every circumstances, are expected to behave in a special way, for instance, whether the women of working class or domestic, literate or illiterate, of young age or old are often, in comparison to males, asked to do all the works related to kitchen. Since the roles of males and females are so fixed that they remain same even after changing the living place (shelter) or home. These roles create sentiments like mental and physical struggle, frustration, ego, satisfaction, happiness, despair etc. that shape the subjective well being. Since our society is patriarchal and follows the feudal values strictly, as result the status of females becomes secondary due to this, we find decline in the status of their subjective well being. On the other hand, males have monopoly even all the resources due to that they carry the subjective well-being. Since our society is patriarchal and follows the feudal values strictly, as result the status of females becomes secondary due to this, we find decline in the status of their subjective well being. On the other hand, males have monopoly even all the resources due to that they carry the subjective well-being 


\section{Subjective Well-Being among Institutionalized and Non- Institutionalized Senior Citizens}

An old woman serves her husband in the same way since her marriage. In spite of reducing physical and mental capacity she serves her husband with more carefully because her husband is growing old gradually but the society and husband do not pay heed that the woman is, too growing old. The same thing has been seen in shelter where woman are ready to help old serve their husband.

Besides it, there is a limitation of age for superannuation but for the domestic work there is no retirement for women. Men consider monopoly over women and deny their personal existence. In spite of being old there are so many lifetime responsibilities over them. From daughter's pregnancy to daughter-in-law's, from birth to look after the grandson and daughters, these responsibility she carries while after a fix age men's life become free from responsibilities.

Finally, the most important and most concrete reasons are that in comparison to males, females are less education and financially helpless that's why they are totally depend upon their husbands. This dependence gives way to many new negative aspects that cause decline in the level of subjective well being. On the other hand, most of the males are educated and financially strong and are head of the family. So consequently, in comparison to females the level of their subjective well-being is greater and we find significant difference between the subjective well being of male elder lies and female elderly. This finding gets a support from the investigation conducted by Shyam \& Yadev (2006). It may be recalled that the investigator in their study, observed that woman had poor well-being as compared to men. Lakshmi and Roopa (2013) are also of the view that there is a significant difference between the institutional and noninstitutional elderly men and women in all the dimensions of quality of life. And male elderly are having more quality of life than female elderly subjects. Contrary to these supportive studies, the study conducted by Suvera (2012) shows the sheer absence of gender effect. According to him the psychological well-being of the institutionalized and non-institutionalized aged cannot be predicted on the basis of their sex.

The F-ratio for the interaction between gender and residential status is 0.1.47, which is statistically not significant at .05 level of confidence. . It means that residential status and gender independently influence subjective well-being of the elderly but when their effects are combined their interactional effect comes to be non-significant, indicating that the individual effects of residential status and gender of elderly subjects dissipate when their effects are combined. It, thus, suggest that to be male elderly and / or non-institutionalized senior citizens is / are sufficient to feel greater amount of subjective well-being.

\section{Acknowledgments}

The author appreciates all those who participated in the study and helped to facilitate the research process.

\section{Conflict of Interests}

The author declared no conflict of interests. 


\section{REFERENCES}

Bockerman, P.,Johansson., E., \& Saarni., I., (2011) Institutionalisation and subjective wellbeing for old-age individuals: is life really miserable in care homes? Ageing \& society 32, 2012,1176-11g2.

Doumit. J., \& Nasser, R., (2010). Quality of life and well-being of the elderly in Lebanese nursing homes. International Journal of Health Care Quality Assurance..23,1, .72-93.

Gull F, Dawood S. Religiosity and Subjective Well-Being amongst Institutionalised Elderly in Pakistan. Health Promot Perspect 2013; 3(1): 124-128

Ku, P.W., McKenna, J., 8 Fox, K.R., (2007). Dimensions of subjective Well-Being and Effects of physical Activity in Chinese older Adults. Journals of Aging and Physical Activity, 15,382 397.

Myers, D.G., \& Diener, E.(1995). Who is happy? Psychology science, 6, 10-19.

Patil, S, S., Itagi, S. K., Khadi, P, B., \& Havaldar, Y,N., (2013). Subjective well-being status among institutionalized and non- institutionalized senior citizens. J sociology Soc Anth, 4(3) 251-257

Singh, R., And Dinesh., (2009). Health Cognitions and subjective well-being in middle-aged and older adults. Journal of Indian health psychology, 4.1.

Stock, W. A., Okun, M. A., Haring, M. J., \& Witter, R. A. (1983). Age and subjective wellbeing: A meta-analysis. In R. J. Light (Ed.), Evaluation studies: Review annual (Vol. 8, pp. 279-302). Beverly Hills, CA: Sage.

Veenhoven, R. (1984). Conditions of happiness. Dordrecht, The Netherlands: D. Reidel Publishing.

How to cite this article: A Dev, M Gufran (2016), Subjective Well-Being among Institutionalized and Non- Institutionalized Senior Citizens, International Journal of Indian Psychology, Volume 3, Issue 4, No. 57, ISSN 2348-5396 (e), ISSN: 2349-3429 (p), DIP: 18.01.033/20160304, ISBN: 978-1-365-23993-9 